\title{
Chemical education and research in Nepal
}

Chemical education in Nepal has a strong potential for nation's development

ESSAY Himalayan Journal of Sciences 1(1): 4-6, 2003Download in PDF format

\author{
Shiva P. Dhoubhadel
}

For the successful economic growth, Nepal needs to be transformed from a commodity based economy to manufacturing based economy and a minimum of $20 \%$ of total manufacturing output should be maintained by chemical industries.

Chemistry is a science of materials at the atomic and molecular level. The knowledge obtained thereby is utilised for solving the problems of man and his environment and society. Chemistry occupies a central position in natural phenomena and in the processes that are the base of technological society. Chemical knowledge is fundamental aspect of our general education because chemicals have a major influence in our daily lives and chemistry is the base upon which many industries operate and upon which new technologies are being developed. We all know that chemistry has contributed to technological revolutions in family planning, medicine, public health, agriculture, newer and more efficient source of energy, metallurgy, textiles, building materials and a large number of other fields of the highest social relevance. Chemistry plays a central role in economic development. Chemical knowledge and technologies are key components in industrial and agricultural development. Chemical knowledge is also crucial to good nutrition and health, and to the overall quality of life. The latest applications of chemical principles are in the areas of environmental protection and conservation providing solution to such problems which arise during developmental planning or by uncontrolled expansions of technology.

\section{Chemistry and development of Nepal}

It is a fact that the crux of the problems of Nepal's economic development lies in the proper utilization of her natural resources such as air, water, mountains, forests, agricultural products and wastes, and the human resource. Proper industrialisation based on development of chemical industries and raw materials or natural resources is another important aspect of her developmental problems. Nepal has to be transformed from a commodity based economy to a manufacturing based economy. This transformation can be achieved by macro-economic and structural adjustment policies and strategies of HMG which can contribute to major inflow by foreign direct investments and the rapid growth of manufacturing sector. The successful growth and transformation of the economy requires the nation to address the challenges of efficient and optimal utilization of existing resources in order to sustain and further improve the national competitiveness. The rapid changes in global trading and investment environment necessitates the enhancement of the competitiveness and resilience of the manufacturing sector. For this, industrial master plan (IMP) including an overall development plan for chemical industries must be drawn. The IMP should thus focus on increasing competitiveness through strengthening industrial linkages, both forward and backward enhancing value added activities and increasing the productivity of the manufacturing sector. The manufacturing sector should overtake the agriculture sector as the engine of growth of the economy and should be the backbone of the Nepalese economy bearing on macro-economic performance of the economy.

Broadly speaking, the manufacturing sector can be classified into resource and non-resource based industries. Resource based chemical industry plays an important role in revitalising and sustaining the long-term growth of economy. Thus chemical industry development in Nepal is very crucial. Chemical industry is a very important part of industries and it must grow in proportion to the rest of the manufacturing economy and should maintain a minimum of $20 \%$ in comparison to the total manufacturing output of a nation. 
support the would-be growing electronic and food processing industries in Nepal. Herein lies the immense importance of our chemical education and research in Nepal.

\section{Brief history}

The beginning of chemical education in Nepal may be traced back to 1921 when I.Sc. level of chemistry teaching took place in T.C. College Kathmandu. B.Sc. level of chemistry teaching started in 1947 in the same college. M.Sc. level of chemical education started in 1965 in T.U. Meanwhile with the mushrooming of I.Sc. and B.Sc. level science teaching campuses in the country, the undergraduate level of chemical education was extended to the whole length and breadth of the country and chemical education assumed the position of national importance. With the recent growth of 10+2 and 3 year B.Sc. programs all over the country, the undergraduate level of chemical education has assumed a colossal dimension in the country which need proper attention and care. Thus the volume of undergraduate chemical education has been very big with its own specific problems and prospects. Academically the huge mass of undergraduate chemical education all over the country is guided by a single chemistry instruction committee composed under the auspices of Central Department of Chemistry, T.U. so far as the affiliates and the university campuses are concerned. The technical institutes have their own separate subject committee for chemistry education. The introduction of multi-university concept in the country has brought some difference of chemistry curriculum from university to university. One notable point is that even after 37 years, the Central Department of Chemistry of Tribhuvan University has remained the only place for post graduate chemical education in Nepal and has played a significant role in the development of chemistry in Nepal. The department offers courses in general chemistry (inorganic, organic and physical) in part I and specialized course in any of the three branches of chemistry in part II.

So far as research in chemistry is concerned, research was initiated on the interest of the concerned teacher and student. There was no regular research program introduced on the regular budget basis. However, on the same basis, the research activity in the department started right from the beginning of the department in 1965. Candidates seeking admission to Ph.D. program used to be academically administered as per Ph.D. rules and regulations of the university, and so far five Ph.D. degree holders have been produced from the department. Also, a number of research publications in international journals have been published regarding the research works conducted in the department. However, research in chemistry has never been a regular program giving the required priority for the activity. Yet, research in the department has established its recognition in the international arena, besides it's standard and recognized M.Sc. teaching program.

\section{Present status}

One of the notable point of present status of chemical education is that new curricula of chemistry in $10+2$, B.Sc. and M.Sc. levels have shown high aspirations for meeting the international standard. $10+2$ and B.Sc. chemistry curricula catering the need of different courses have wide variations in the matter of objectives and its achievements. So, the programs are fully managed by the individual campuses themselves as per their capacity and facilities. It is beyond the control of T.U. Regarding M.Sc. chemistry teaching the department, T.U. has seen its big change in its program which started with 12 students in 1965 and new enrolls 180 student in each year. At present 90 students are enrolled annually in the program.

At present the department in its running partwise program has about 180 students distributed into three different branches of chemistry namely inorganic, organic and physical. The enrollment of students in chemistry has been in increasing trend. The students are admitted on the basis of entrance examination in the part first program. In the part second, there is specialization as well as offering of electives e.g. natural products, nuclear chemistry, spectroscopy. Upgrading the facilities within the department to keep pace with pressure of enrollment has been inadequate, and the department is struggling very hard. Some facilities in terms of sophisticated instruments have been added under the Higher Education Project (HEP). The department has now annex building constructed under H.E.P. So, there is not problem of space but the department has not been able to run those newly added sophisticated instruments properly and regularly because of the lack of budget for bringing them into working conditions. At present, the fields of research have been in the following areas: synthetic chemistry, reaction mechanism, natural product chemistry, solid state chemistry, electrochemistry, analytical chemistry, radio chemistry, applied enzymology and biotechnology, chemistry of clay minerals, environmental chemistry, organic sulphur chemistry.

Many part time teachers are working in the department. The department is unable to defray their remuneration in time. However, the department has carried out extra curricular activities, seminars, symposia and talk programs which are very useful to both students and teachers. In this respect, the department has a vibrant atmosphere. 
Chemistry and it's achievements in the Nepalese context

Since the inception of chemical education in Nepal, the problem of supplying low, medium and high chemistry manpower needed for the country has been solved. Many students of chemistry have been working in various developmental laboratories, in industries and in private laboratories in Nepal. Many have rendered services in disseminating chemistry knowledge by teaching. Many are serving in health, agriculture and other fields in Nepal. Beside this, a number of students have been able to work in various laboratories and institutions worldwide.

Our chemists are competent enough for designing the programs for the applications of chemistry in the development of nation. Be it with reference to her natural products, that are still awaiting to be exploited, or proper utilization of her water and vast hydropower, or the sustainable development of her agriculture, or her industrialization which is in infancy and has not been able to provide challenges for chemists. Thus the importance of chemical education and research in Nepal may again be emphasized.

Shiva P. Dhoubhadel is a professor of chemistry in Tribhuvan University.

Phone: 023-1-4411761 (R) 